\title{
SCBA CEMENTITIOUS MATERIALS FOR MODERN CONSTRUCTION
}

\author{
Dr. Shanthala $B$ \\ Assistant Professor, Department of Civil Engineering \\ Government Engineering College, Karwar, Karnataka.
}

\begin{abstract}
The construction of modern structures calls for materials with increasingly improved properties like strength, stiffness, toughness, ductility and finally durability. It is essential that when concrete is use for modern structures, then it should retain its original form, quality, and serviceability throughout its lifespan without any deterioration that is, it should have long durability. Durability of concrete depends on strength of concrete also. Strength is definedas ability of concrete to carry load. Now-a-days concrete with varieties of strength are available as per requirements. Cost of concrete too varies with strength. Even though strength is a key factor, only limited studies are carried out to investigate the addition of Sugar Cane Bagasse Ash (SCBA). In this study, therefore we firstly an attempt has been to study the effect of addition of Sugar Cane Bagasse Ash and which gives the maximum strength on test result on compression strength of low grade concrete (M25). The present paper main objectives are the present study aims at mix design of M25 grade of concrete and to find required constitutes of it. The study the effect of replacement of cement in concrete by pozzolanic material that is Bagasse Ash. To study the effect of addition of Sugar Cane Bagasse Ash (0\%, 5\%, 10\%, and 15\%) on compressive strength of low-grade concrete (M25). To study the effect of addition of Sugar Cane Bagasse Ash (0\%, 5\%, $10 \%$, and 15\%) ontensile strength of low-grade concrete (M25). To find out the optimum percentage of Bagasse Ash that can effectively replaces the cementbweight without any adverse effect on properties of hardened concrete.
\end{abstract}

\section{Keywords- SCBA, durability, pozzolanic, hardened concrete}

\section{INTRODUCTION}

Concrete is the most widely used construction material in the world, more so in the developing countries, and there are global concerns such as depletion of non-renewable mineral deposits and emission of the greenhouse gas associated with the manufacture of cement, which is the primary binding agent in concrete. Therefore, the need for economical and more environmental-friendly cementing materials have increased the interest in other cementing materials that can be used as partial or total replacements of the normal Portland cement. Many efforts have been made to increase the use of supplementary cementitious materials (SCMs) in concrete production because cement production consumes high energy and is responsible for $5 \%$ of global carbon dioxide (CO2) emissions (1 ton of cement produces about 1 ton of carbon dioxide) and the use of SCMs can also improve the performance of concrete.

Many industrial wastes and by products such as fly ash, blast furnace slag, and silica fume etc. are used as SCMs in concrete production. Amorphous silicon dioxide ( $\mathrm{SiO} 2)$ present in such pozzolanic materials leads to the formation of additional calcium silicate hydrate(CS-H) when it reacts with calcium hydroxide (free lime formed during cement hydration) and water. This is called secondary gel. This additional $\mathrm{CSH}$, thus formed, increases the density of the matrix and improves the pore structure leading to better durability of concrete and most of the time results in increase in strength also This use of industrial wastes has reduced the dumping land requirements and leads to creation of wealth from waste. Similarly agro-industrial wastes such as rice husk ash and wheat straw ash have been found to have good pozzolanic properties. This is due to the presence of high $\mathrm{SiO} 2$ content in them and its amorphous nature, which is governed by the burning conditions and usually controls the improvement in strength and durability of the end product. Bagasse, an abundantly produced agricultural waste, is the residue of sugarcane that is obtained after extraction of juice. Next only to Brazil, India is the second largest producer 13 of sugarcane in the world with annual production in the year 2011 set to exceed 300 million tonnes .It is estimated that the processing of this sugarcane in sugar mills results in the production of approximately 100 million tonnes of wet sugarcane bagasse every year. The bulk amount of bagasse waste produced in sugar factories requires a meaningful disposal scheme. The increasing cost of natural gas and fuel oil has resulted in high prices of electricity and has contributed the practice of using sugar cane bagasse as fuel in the cogeneration plants due to its good calorific properties.

Burning of bagasse as fuel leaves bulk quantity of ash called sugarcane bagasse ash (SCBA) whose disposal poses serious threat to the environment and requires land for dumping. Bagasse ash (BA) has pozzolanic properties and so its use in concrete as SCM has been investigated by a few authors. The review of these studies along with the highlights has been discussed in the following sections. Thus this chapter presents the summary of research efforts on use of bagasse ash as SCM in concrete.

Manu Santhanam :In his literature says that raw bagasse ash has low pozzolanic activity and high loss on ignition due to the presence fibrous unburnt carbon particles. Removal of the fibrouscarbon particles from raw bagasse ash, and further grinding to cement fineness was seen to significantly improve its pozzolanic activity. Durability performance of SCBA-based Portland pozzolana cements was investigated by five different methods. Blended 
cements were ground to similar fineness as OPC to completely exclude filler effect. Observed reduction in permeability with increase in SCBA replacements is purely from pozzolanic performance of SCBA. The oxygen permeability test showed only marginal increase in OPI for SCBA-blended cements. However, remarkable reduction in air permeability was observed for SCBAreplaced specimens than control concrete in Torrent air permeability test. Durability performance of SCBA-based Portland pozzolana cements against chloride permeability and water penetration were studied. Incorporation of SCBA in concrete substantially enhanced the resistance against water penetration and chloride permeability. Prominent reduction in permeability of concrete with increase in SCBA replacements is due to superior pozzolanic performance of SCBA as well as enhancement in the pore structure as a result of pore refinement. SCBA can be used as supplementary cementitious material to achieve durable concrete[1].

Anil Pratap Singh(2015); They studied on " Effect of use of Bagasse Ash on Strength of Concrete", with increasing demand and consumption of cement, researchers and scientist are in search of developing alternate binders that are eco friendly and contributes towards waste management .In these paper SCBA has been chemically and physically characterized and partially replaced in the ratio of $0 \%, 5 \%, 10 \%, 15 \% \& 20 \%$ by weight of cement in concrete. The properties for fresh concrete are tested like slump cone test and for hardened concrete compressive strength at the age of $7 \& 28$ days by using grade M30.The test result indicate that the strength of concrete increase up to $10 \%$ SCBA replaced with cement[2].

R Srinivasan and K. Sathiya (2010); They studied on "Experimental Study on Bagasse Ash in Concrete". The utilization of industrial and agricultural waste produced by industrial processes has been the focus of waste reduction research for economic, environmental, and technical reasons. Sugar-cane bagasse is a fibrous waste-product of the sugar refining industry, along with ethanol vapor. This waste product (Sugar-cane Bagasse ash) is already causing serious environmental pollution, which calls for urgent ways of handling the waste. Bagasse ash mainly contains aluminum ion and silica. In this paper, Bagasse ash has been chemically and physically characterized, and partially replaced in the ratio of $0 \%, 5 \%, 15 \%$ and $25 \%$ by weight of cement in concrete. Fresh concrete tests like compaction factor test and slump cone test were undertaken was well as hardened concrete tests like compressive strength, split tensile strength, flexural strength and modulus of elasticity at the age of seven and 28 days was obtained. The test result indicate that the strength of concrete increase up to $15 \%$ SCBA replacement with cement[3].

Sirirat Janjaturaphan and SupapornWansom (2010); They studied on, "The Pozzolanic Activities of Industrial Sugar Cane Bagasse Ash". They find out the chemical composition of the Sugarcane Bagasse Ash and compared them with the other pozzolanic material that is, rice husk ash and concluded that the SCBA is suitable for the partial replacement of cement[4].

D. Mukharjee (2011)has Study made on "Utilization of SCBA". They described the various uses of SCBA in agriculture, construction, use of bagasse as fertilizers; in horticulture etc. their chemical and other fertilizing properties etc. also gave various options for utilizing bagasse ashin various fields. Ashes obtained after control burning of SCB at $600 \mathrm{oC} / 5$ hour were reasonably reactive given by the fact that little crystallization of minerals occurred. Morphological, XRD and TGA/DTA study of the blended pastes confirmed the hydration reaction of SCBA within the cement gel. Compressive and flexural strength tests confirmed the actual behavior of SCBA blended mortars and it suggested that up to $15 \%$ substitution of OPC with SCBA can be made with better strength results than that with pure cement[5-9].

\section{MATERIALS AND METHODOLOGY}

\subsection{Material Used}

Cement- Ordinary Portland cement of 53 grade from a single batch was used for the entire work and care has been taken that it has to been stored in airtight containers to prevent it from being affected by the atmospheric and monsoon moisture and humidity. The cement procured was tested for physical requirements in accordance with IS:12269-1987

Sugarcane Bagasse Ash- Sugarcane bagasse consists of approximately $50 \%$ of cellulose, $25 \%$ of hemicelluloses of lignin. Each ton of sugarcane generates approximately $26 \%$ of bagasse (at a moisture content of $50 \%$ ) and $0.62 \%$ of residual ash. The residue after combustion presents a chemical composition dominates by silicon dioxide (sio2). In spite of being a material of hard degradation and that presents few nutrients, the ash is used on the farms as a fertilizer in the sugarcane harvests.

Fine Aggregate: The locally available river sand is used as fine aggregate in the present investigation. The sand is free from clay, silt and organic impurities

Crushed stone aggregate of $20 \mathrm{~mm}$ size, which was locally available, was used as coarse aggregate. All coarse aggregate used were angular in shape.

Potable water free from deleterious materials viz.oil and other impurities such as chloride was used for casting of concrete specimens. The water was found suitable for concrete mixing and curing as per IS 456: 2000.

\subsection{Casting of Specimen}

Mixing of ingredients is done in concrete mixing sheet. The fine aggregate and coarse aggregate are thoroughly mixed and then the cement is added and mixing is done until a mixture of uniform colour is obtained. Then SCBA added and blended nicely with specified water content. casting is done in cast iron cubes of standard dimensions of $(150 \mathrm{~mm} \times 150 \mathrm{~mm} 150 \mathrm{~mm})$. The cast iron moulds are cleaned of dust particles and applied with mineral oil on all sides before concrete is poured in to the moulds. The moulds are placed on a level platform. The well mixed concrete is filled in to the moulds with proper compaction. Excess concrete was removed with trowel and top surface is finished level and smooth as per IS 516-1969.

\subsection{Curing}

The specimens are left in the moulds undisturbed at room temperature for about 24 hours after casting. The specimens are then removed from the moulds and immediately transferred to the different curing tank i.e. cubes are cured in 
fresh water. A time schedule for testing of specimens is maintained to ensure their proper testing on the due date and time. The cast specimens are tested as per standard procedures, immediately after they are removed from curing tubs and wiped off the surface water, as per IS 516-1959.

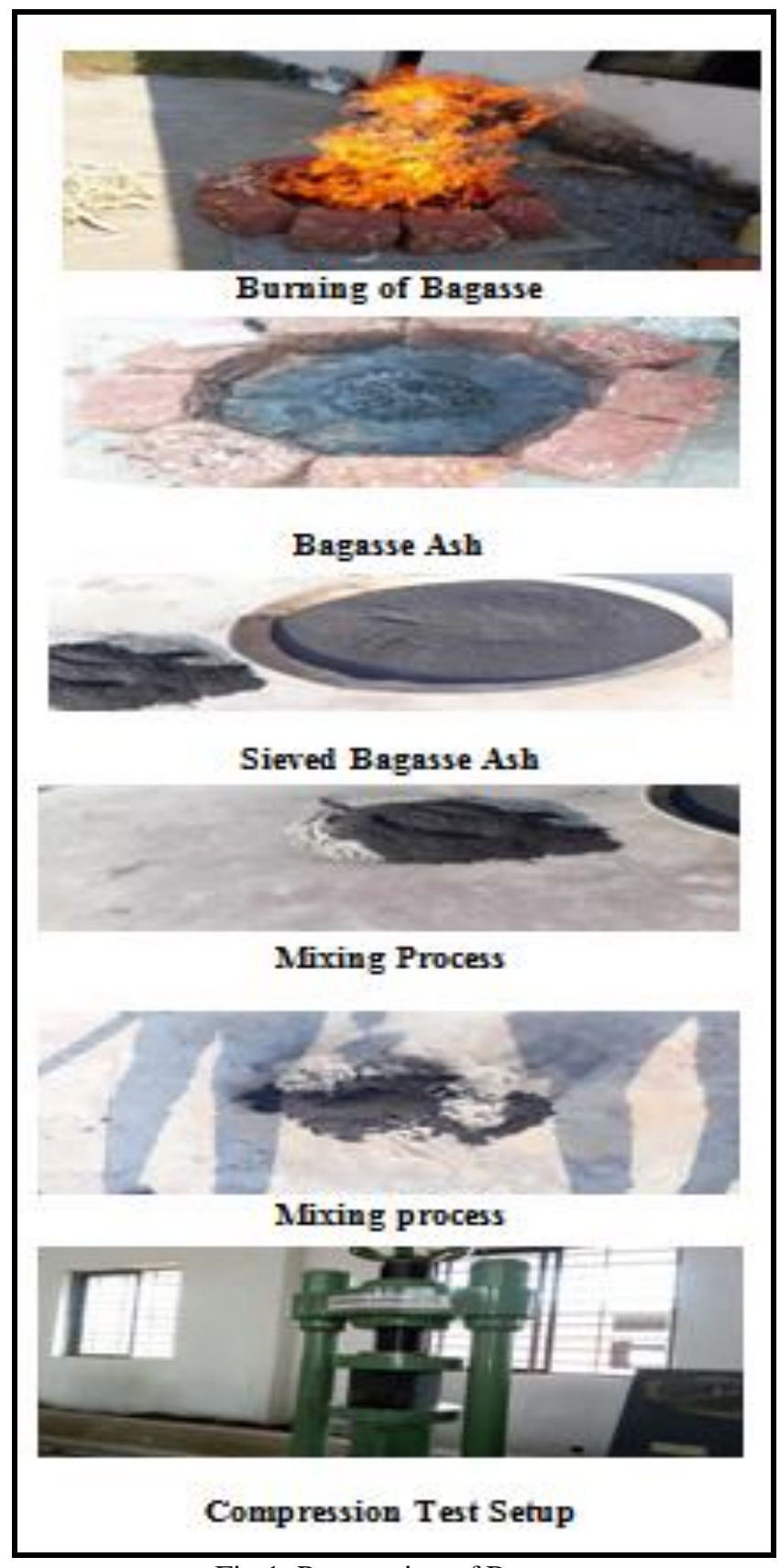

Fig.1. Preparation of Bagasse

\section{RESULTS AND DISCUSSIONS}

Concrete cubes of size $150 \times 150 \times 150 \mathrm{~mm}$ were casted and tested for compressive strength in normal water at ages of 7 , 28 days for $10 \%, 20 \%, 30 \%$ replacement of sugarcane bagasse ash for M25 grade of concrete.

The results indicate that the compressive strength of concrete increases up to a percentagereplacement of $10 \%$ after which there is a gradual drop in compressive strength. The water absorption percentage increases with percentage of SCBA replaced.
Table. 1. Physical \& Chemical Properties of OPC, Sugarcane Bagasse Ash.

\begin{tabular}{|c|c|c|}
\hline Properties & Ordinary Portland Cement & Sugarcane baggase ash \\
\hline \multicolumn{3}{|c|}{ Physical properties } \\
\hline Initial Setting Time (Min) & 115 & $\cdot$ \\
\hline Final Setting Time (Min) & 229 & 2.12 \\
\hline $\begin{array}{c}\text { Specific Gravity } \\
\text { Fineness as Surface Area } \\
\text { (m2/kg) }\end{array}$ & 3.15 & 410 \\
\hline \multicolumn{2}{|c|}{ Chemicalproperties } \\
\hline Slicon dioxide(SiO2) & $21.02 \%$ & $70.97 \%$ \\
\hline $\begin{array}{c}\text { AluminiumOxide (Al203) } \\
\text { Ferric Oxide (Fe203) }\end{array}$ & $5.68 \%$ & $8.55 \%$ \\
\hline Magnesium Oxide (MgO) & $3.53 \%$ & $3.61 \%$ \\
\hline Calcium Oxide (CaO) & $1.1 \%$ & $2.83 \%$ \\
\hline Sulphur Trioxide(SO3) & $62.25 \%$ & $6.50 \%$ \\
\hline Sodium Oxide (Na20) & $3 \%$ & $0.80 \%$ \\
\hline Potassium Oxide (K20) & $0.15 \%$ & $0.92 \%$ \\
\hline
\end{tabular}

\section{COMPRESSIVE STRENGTH TEST:}

Grade of Concrete: M25

Size of block: 150 × 150 x $150(\mathrm{~mm})$,

Curing : 7days, 28days.

No of Blocks : 3 Blocks

Table.2. Compressive Strength Test Results

\begin{tabular}{|c|c|c|}
\hline AMOUNT OF SCBA IN \% & \multicolumn{2}{|c|}{ AGING } \\
\cline { 2 - 3 } & 7 DAYS & 28 DAYS \\
\hline 10 & 49.77 & 84.44 \\
\hline 20 & 31.1 & 40 \\
\hline 30 & 18.66 & 22.22 \\
\hline
\end{tabular}

Table.3. Water Absorption Test Results

\begin{tabular}{|c|c|c|c|}
\hline \multirow{2}{*}{$\begin{array}{c}\text { AMOUNT OF SCBA } \\
\text { IN \% }\end{array}$} & \multicolumn{3}{|c|}{ AGING } \\
\cline { 2 - 4 } & 24 HOURS & 7 DAYS & 28 DAYS \\
\hline $10 \%$ & $4.3 \%$ & $4.6 \%$ & $4.9 \%$ \\
\hline $20 \%$ & $5.4 \%$ & $5.8 \%$ & $6.1 \%$ \\
\hline $30 \%$ & $7.9 \%$ & $8.3 \%$ & $8.5 \%$ \\
\hline
\end{tabular}

\section{CONCLUSION}

Based on the experimental and analytical investigations, the Present work Replacement of cement by bagasse ash reduce industrial waste and to save cement. By saving cement reduced greenhouse gases emission and makes environmental green. As the percentage of sugarcane bagasse ash increases the compressive strength of concrete tends to increase up to certain percentage and then start's decreasing with the increase of ash content. Water requirement increased as the percentage of BA increased. Bagasse ash is a valuable pozzolanic material and it can potentially be used as a partial replacement for cement. And make construction cheaper. This could reduce the environmental problems and minimize the requirement of land fillarea to dispose BA.

\section{REFERENCES}

[1] Bahurudeen, A. and M. Santhanam, 2014. 'Sugarcane bagasse ash - an alternative supplementary cementitious material', In Proceedings International conference on advances in civil 
engineering and chemistry of innovative materials, India, pp: $837-4$

[2] Bahurudeen, A., A.V. Marckson, Arun Kishore andManu Santhanam, 2014. 'Development of sugarcane bagasse ash based Portland pozzolana cement and evaluation of compatibility with superplasticizers', 2014, Cement \& Concrete Composites, 68: 465-475.

[3] Bahurudeen, A., Deepak Kanraj, V. Gokul Dev and Manu Santhanam, 2015. 'Performance evaluation of sugarcane bagasse ash blended cement in concrete', 2015, Cement \& Concrete Composites, 59: 77-88.

[4] Cordeiro, G.C., R.D. Filho, L.M. Tavarse and E.M. Fairbairn, 2009. 'Ultrafine grinding of sugarcane bagasse ash for application as pozzolanic admixture in concrete' 2009 Cement Concrete Research, 39: 110-115.

[5] Chusilp, N., C. Jaturapitakkul and K. Kiattikomol, 2009. 'Effects of LOI of ground bagasse ash on the compressive strength and sulfate resistance of mortar' 2009, Construction Building Materials, 23(12): 3523-3531.

[6] Frias, M., E. Villar and H. Savastano, 2011. Brazilian sugar cane bagasse ashes from the cogeneration industry as active pozzolans for cement manufacture. Cement Concrete Composite,33: 490-496.

[7] Ganesan, K. and M. Rajagopal Thangavel, 2007. 'Evaluation of bagasse ash as supplementary cementitious material', Cement Concrete Composite, 29: 515-524.

[8] Rattapon Somna, Chai Jaturapitakkul, Pokpong Rattanachu and Wichian Chalee, 2012. Effect of ground bagasse ash on mechanical and durability properties of recycled aggregate concrete', 2012, Materials and Design, 33: 597-603.

[9] Kawee Montakarntiwong, Nuntachai Chusilp, Weerachart Tangchirapat, Chai Jaturapitakkul, 2013. 'Strength and heat evolution of concretes containing bagasse ash from thermal power plants in sugar industry', Materials and Design, 49: 414420. 